\title{
TREATMENT OF SLIPPED UPPER FEMORAL EPIPHYSIS
}

\author{
F. C. Durbin, Exeter, England
}

Slipping of the upper femoral epiphysis has been recognised since 1572 when it was first described by Paré, but its cause has not yet been fully determined. Treatment has been a controversial subject since the late nineteenth century when operative measures were first practised. The pendulum for and against operation has been swinging ever since, with a bias towards conservative treatment.

The condition is relatively uncommon and therefore the collected results of a large series are valuable. After a study of slipped femoral epiphysis carried out by a sub-committee of the British Orthopaedic Association, Hall (1957) reported on the results of all forms of treatment in 173 hips in 138 patients representing a random sample of the results in the United Kingdom in recent years. The results of a previously unreported series of eighty-one hips in sixty-three patients are presented here (Table I). The series is comparable to Hall's except that all hips have been compared with a standard of normal mobility of 85 (Gade's indices). Although Gade produced an index of 100 for a normal hip Hall estimated it to be 90 in fifty normal hips and we found it to be 85 . Assessment of functional activity followed Hall's modification of Shepherd's (1954) plan (Table II).

The results in the series as a whole are comparable with those found by Hall (1957) (Table III, Fig. 1).

TABLE I

Analysis of Material Studied

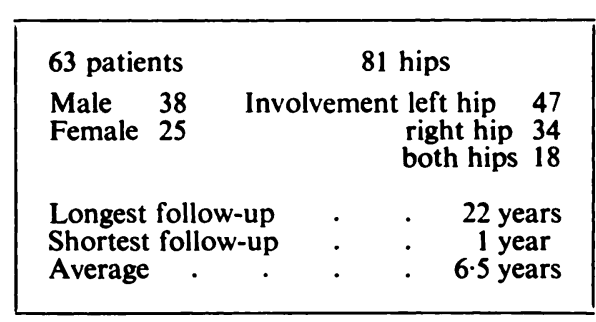

\section{CONSERVATIVE TREATMENT}

Failure to prescribe treatment might be considered negligent; yet, as Howorth (1957) has reminded us, we carry a heavy responsibility when we undertake treatment. The condition always heals without treatment and the results in untreated hips are often good, for avascular necrosis seldom occurs and disability before middle life is rare.

In very early cases further slipping can be prevented by rest in bed, plaster splintage or the use of a walking caliper. Such treatment must be prolonged because the epiphysis may not fuse for several years, and, until fusion has occurred, further slipping is possible. Slipping recurred three times in the present series after conservative treatment-once eighteen months after primary treatment had ceased. If prolonged, plaster splintage may lead to restricted mobility of the hip; and it promotes chronic invalidism and interferes seriously with the child's education at an important stage when examinations may be approaching. Furthermore, conservative treatment may fail and lead to an imperfect result (Table IV).

Formerly, hips with unacceptable degrees of displacement have been forcibly manipulated or treated with powerful traction regardless of the duration of symptoms. There is no doubt 
F. C. DURBIN

TABLE II

Summary of Factors Considered in Arriving at a Final Assessment (Modified from Shepherd and Hall)

\begin{tabular}{|c|c|c|c|c|}
\hline & Pain & Index of mobility & Function by performance & \\
\hline Excellent & None or ignores & Over 80 & 1 black mark & $\begin{array}{l}\text { Incongruent joint surfaces, } \\
\text { gross displacement, } \\
\text { osteoarthritic lipping }\end{array}$ \\
\hline Good . & None or ignores & $70-80$ & Up to 3 black marks & or narrow joint space \\
\hline Fair & Concessions & $45-70$ & Up to 5 black marks & $\begin{array}{c}\text { in a sub-category } \\
\text { with }\end{array}$ \\
\hline Poor & Disabling & Under 45 & 6 or more black marks & \\
\hline
\end{tabular}

TABLE III

Results in the Series as a Whole, Compared WITH THOSE FOUND BY HaLl

\begin{tabular}{|c|c|c|}
\hline & Present series & Hall's figures \\
\hline & \multicolumn{2}{|c|}{ Percentages } \\
\hline Excellent & $39 \cdot 6$ & $48 \cdot 3$ \\
\hline Good & $35 \cdot 8$ & $29 \cdot 6$ \\
\hline Fair & $12 \cdot 3$ & 6.9 \\
\hline Poor & $12 \cdot 3$ & $15 \cdot 2$ \\
\hline
\end{tabular}

TABLE IV

Conservative Treatment:

RESUlts IN NiNETEEN HIPS

\begin{tabular}{|lccc|}
\hline & \multicolumn{2}{c}{ Present series } & Hall's figures \\
& \multicolumn{3}{c}{ Percentages } \\
\hline Excellent & 37 & $35 \cdot 5$ \\
Good. & 37 & 39.9 \\
Fair. & 5 & $12 \cdot 3$ \\
Poor. & 21 & $12 \cdot 3$ \\
\hline
\end{tabular}

TABLE V

Effects of Manipulation on all Treatment Excluding Osteotomy Hall's figures are in bold type

\begin{tabular}{|c|c|c|c|c|c|c|c|c|}
\hline \multirow[b]{3}{*}{ With manipulation } & \multicolumn{2}{|c|}{ Excellent } & \multicolumn{2}{|c|}{ Good } & \multicolumn{2}{|c|}{ Fair } & \multicolumn{2}{|c|}{ Poor } \\
\hline & \multicolumn{8}{|c|}{ Percentages } \\
\hline & 43 & $27 \cdot 2$ & 18 & $45 \cdot 4$ & 21 & $18 \cdot 2$ & 18 & $9 \cdot 1$ \\
\hline Without manipulation 32 hips & 56 & 43.8 & 44 & $34 \cdot 4$ & 0 & $6 \cdot 3$ & 0 & $15 \cdot 6$ \\
\hline
\end{tabular}

TABLE VI

Subluxation of Hip Resulting from Traction

\begin{tabular}{|lrrrrr|}
\hline Abduction frame & $\cdot$ & $\cdot$ &. &. & 1 \\
Skin traction &. &. &. &. & 1 \\
Skeletal traction & $\cdot$ & $\cdot$ & $\cdot$ & $\cdot$ & $\frac{2}{4}$ \\
& Total &. &. & \\
\hline
\end{tabular}


that hips which have been manipulated present worse results than those which have not. whatever the subsequent treatment may be (Table V, Fig. 2). Manipulation must be gentle if it is used at all.

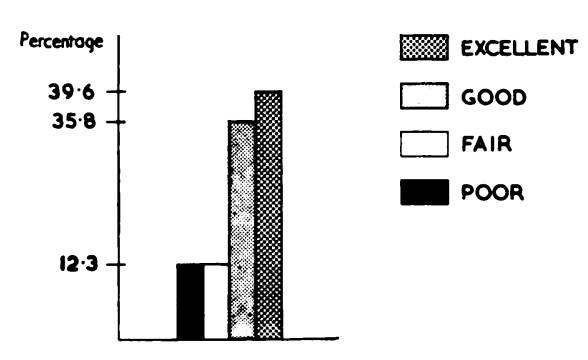

FIG. 1

Results in the whole series of eighty-one hips in sixty-three patients.

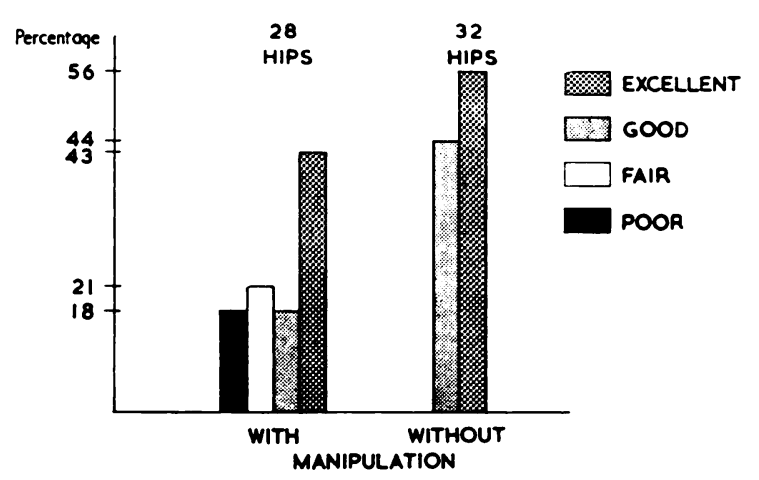

FIG. 2

Results of treatment with and without manipulation.

Traction must be used with care because the hip may be subluxated or dislocated, especially by skeletal traction and even with skin extension or with traction on an abduction frame (Table VI, Figs. 3 and 4).

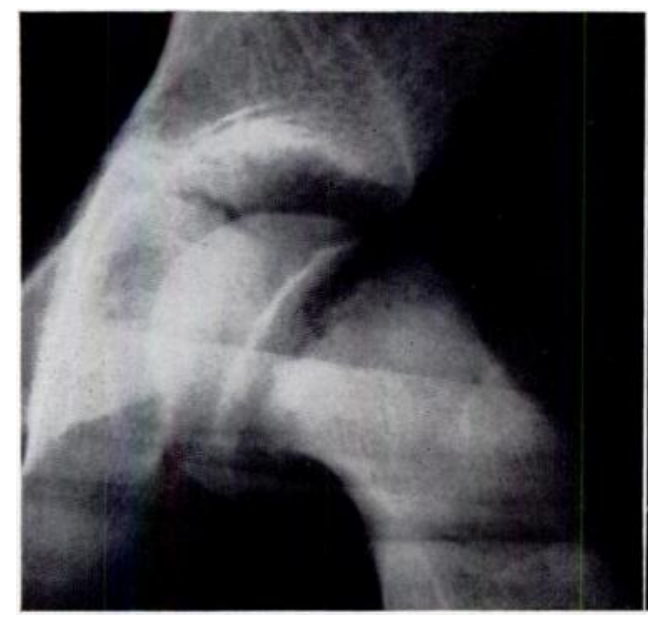

Fig. 3

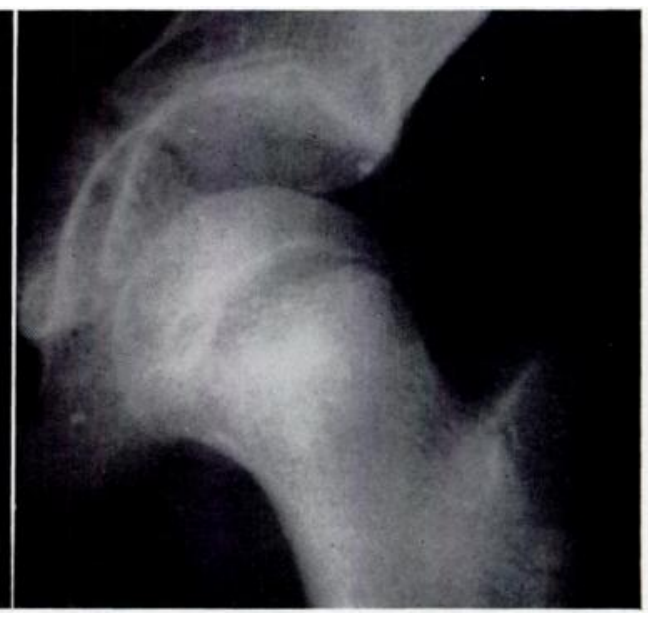

Fig. 4

Figure 3-An acute slip of the left epiphysis. Figure 4-Reduction achieved by straight traction for twelve hours, but subluxation of the head of the femur has occurred.

\section{OPERATIVE TREATMENT}

The early literature of this has been extensively reviewed by Howorth (1957). In the days before radiography, correction of the deformity by a subtrochanteric osteotomy had been obtained by Keetley (1888) and Bradford (1892). Sturrock in 1894 used internal pin fixation of the epiphysis but the result was a failure. Later, Whitman (1909) reported a series of eight cases of open reduction of the slipped epiphysis. Ferguson and Howorth (1931) drilled holes through the epiphysial plate and inserted small bone grafts into them in order to promote quick fusion of the epiphysis to prevent further displacement. They also reported on the pathology of bone and synovial material removed by them at the time of operation. 
Wilson (1938) recognised that there were two main groups of patients-those with minimal displacement and those with advanced deformity. Patients treated early obtained excellent results and therefore their early recognition was important. He advised immediate fixation of the epiphysis by insertion of a Smith-Petersen nail. Then Klein, Joplin and Reidy (1948) led a revival of open reduction by cervical osteotomy combined with Smith-Petersen nailing.

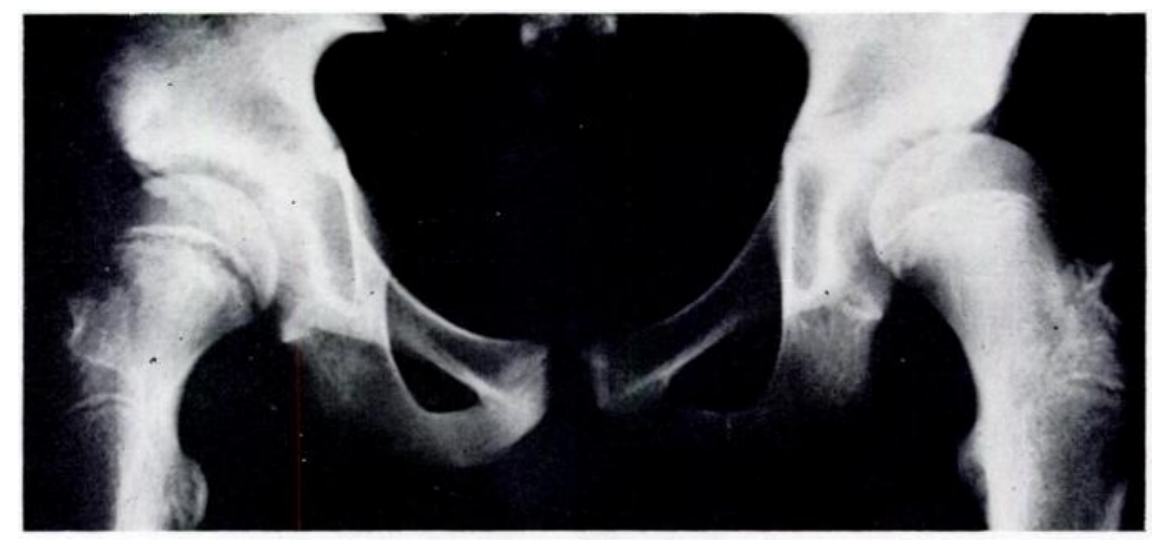

Fig. 5

An early slip of the right epiphysis, and the normal left hip for comparison.

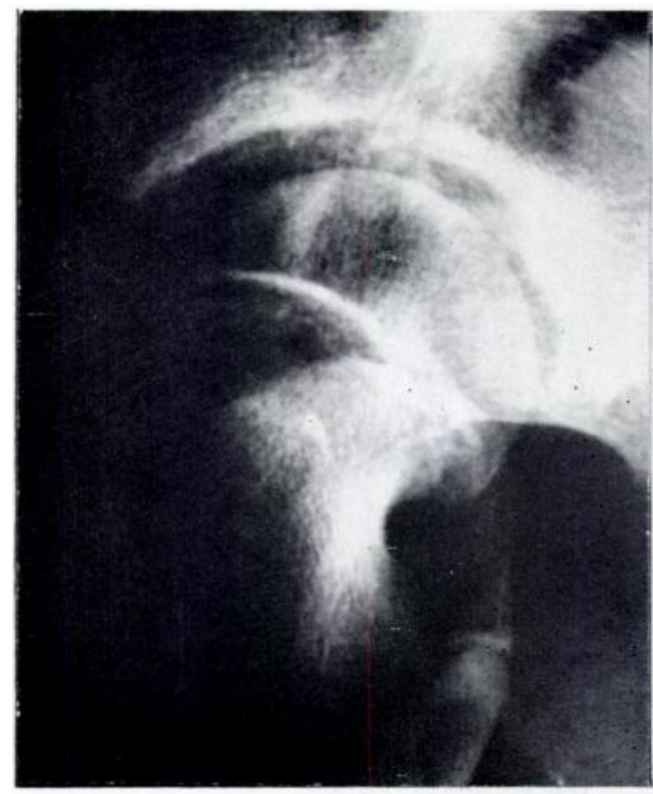

FIG. 6

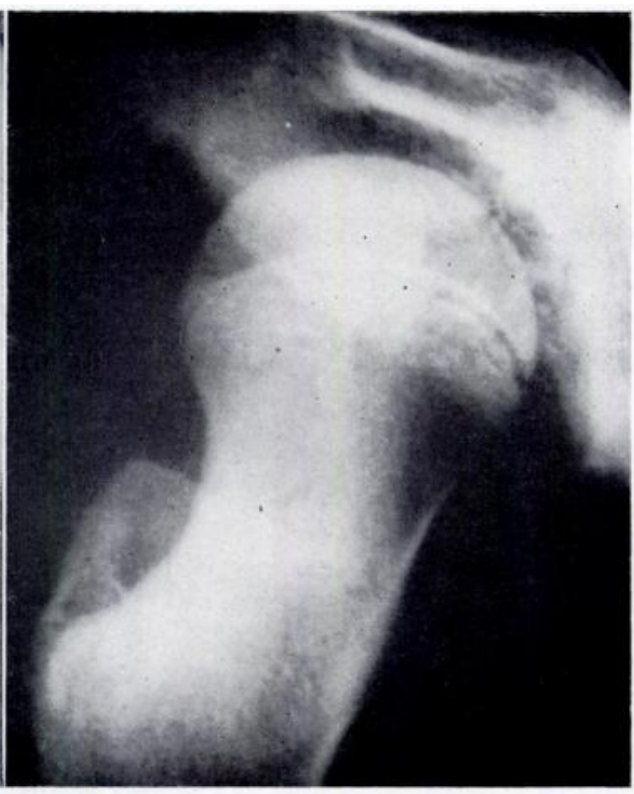

FIG. 7

Lateral radiographs of the same hips as in Figure 5 showing the degree of displacement of the right epiphysis.

Their high proportion of successful results has not been confirmed and this procedure is now seldom performed. All observers are agreed that when the slip is of long standing any form of treatment is a salvage procedure.

Unquestionably the best results are by treatment of the minimal slip at an early stage, the epiphysis being fixed so that it can displace no further. This necessitates better education 
of the family doctor in the early symptoms and signs, for many patients have symptoms for several months before the diagnosis is made at hospital. Howorth's view is that to diagnose the early case it is most important to think of the possibility, examine the hip carefully and obtain good radiographs.

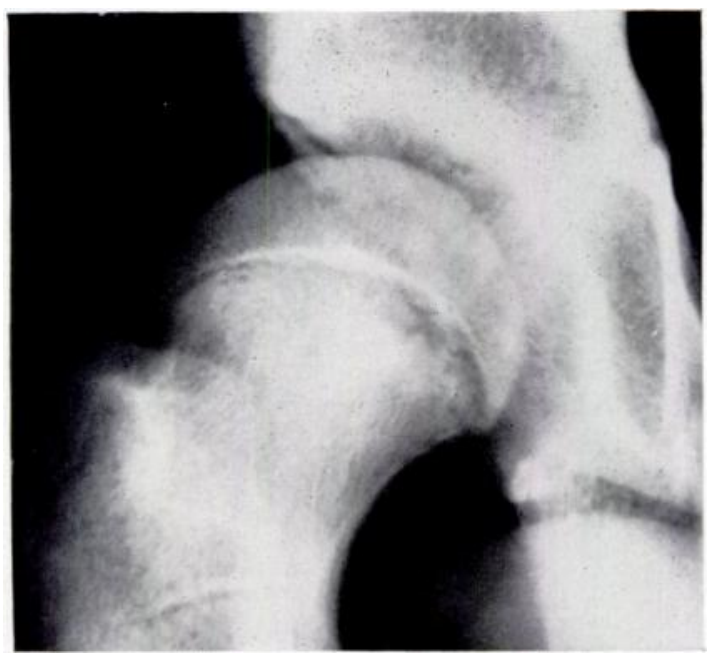

Fig. 8

An early slip showing the characteristic "beak" appearance of the epiphysis. The so-called step up from the neck of the femur to the epiphysis is still present.

The radiographic diagnosis is not always easy, especially when the epiphysis is displaced backwards and not medially, as it may be missed in the antero-posterior view (Figs. 5 to 7). In the early case there is a characteristic beak-like appearance of the inferior angle of the slipped epiphysis at its junction with the inferior surface of the neck of the femur (Fig. 8).

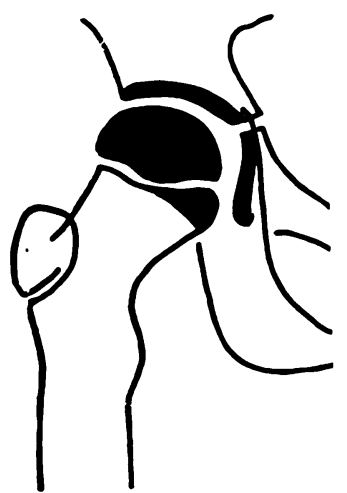

INFANTILE

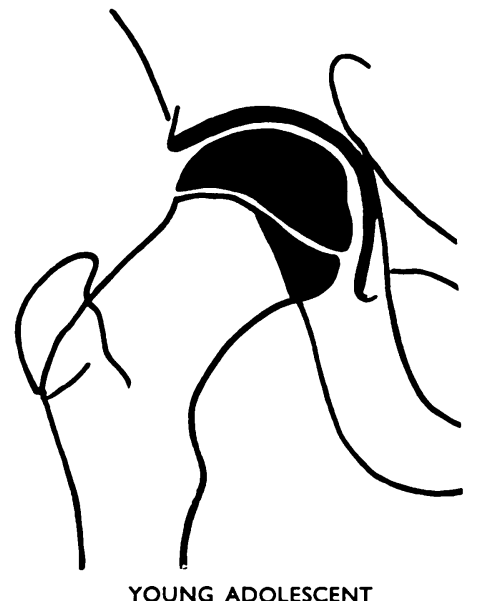

FIG. 9

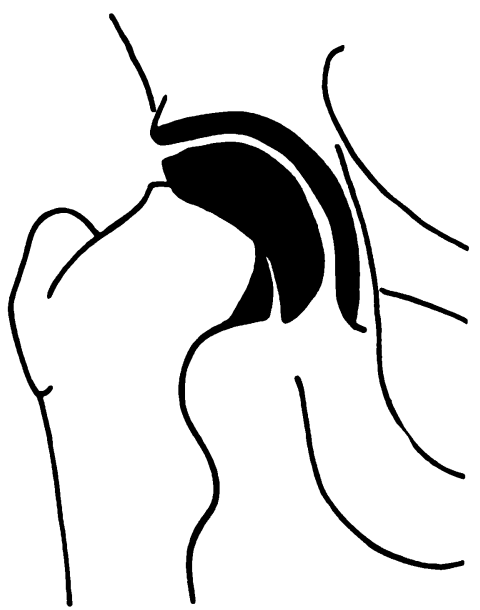

EARLY EPIPHYSIAL SLIP

Diagram showing how the diaphysis extends medially under the epiphysis, forming part of the articular femoral head in the infant and young adolescent. The exclusion from the acetabulum of this articular portion of the diaphysis by the downward and backward thrust of the epiphysis is one of the earliest radiological signs of adolescent slipping of the upper femoral epiphysis (Capener 1956). The downward pointing epiphysial beak is apparent even when the displacement is less than that shown in the drawing. Blue-The morphological capital epiphysis. The acetabulum and diaphysial contribution to the adult articular head are red.

VOL. 42 B, NO. 2, MAY 1960

$$
\mathrm{H}-\mathbf{1}_{(8)}
$$


TABLE VII

Comparison of Results of Conservative Treatment, Smith-Petersen Nalling and Multiple Pinning Hall's figures are in bold type

\begin{tabular}{|c|c|c|c|c|c|c|c|c|c|}
\hline \multirow[b]{3}{*}{ No operation-19 hips. } & & \multicolumn{2}{|c|}{ Excellent } & \multicolumn{2}{|c|}{ Good } & \multicolumn{2}{|c|}{ Fair } & \multicolumn{2}{|c|}{ Poor } \\
\hline & & \multicolumn{8}{|c|}{ Percentages } \\
\hline & . & 37 & $35 \cdot 5$ & 37 & 39.9 & 5 & $12 \cdot 3$ & 21 & $12 \cdot 3$ \\
\hline Nailing-14 hips . & . & 57 & 68.9 & 22 & $18 \cdot 8$ & 14 & $4 \cdot 2$ & 7 & $8 \cdot 4$ \\
\hline Multiple pinning -27 hips & . & 52 & 80 & 37 & 20 & 11 & $\mathbf{0}$ & $\mathbf{0}$ & $\mathbf{0}$ \\
\hline
\end{tabular}

It is not sufficiently realised that the caput femorale comprises more than the capital epiphysis. The diaphysis extends medially under the epiphysis and forms part of the articular femoral head. Capener (1956) has shown that the exclusion from the acetabulum of this articular part of the diaphysis by the downward and backward thrust of the epiphysis is amongst the earliest radiological signs of slipping (Fig. 9).

Treatment in cases with slight displacement-When a slight displacement has been recognised the epiphysis should be fixed surgically as Wilson (1938) advised. The Smith-Petersen nail, however, has certain disadvantages: its large bulk may sometimes render its insertion difficult. The healing reaction at the site of the slip tends to prevent the entry of the bulky nail as it reacts like rubber and diminishes the force of the hammer blow besides causing resistance.

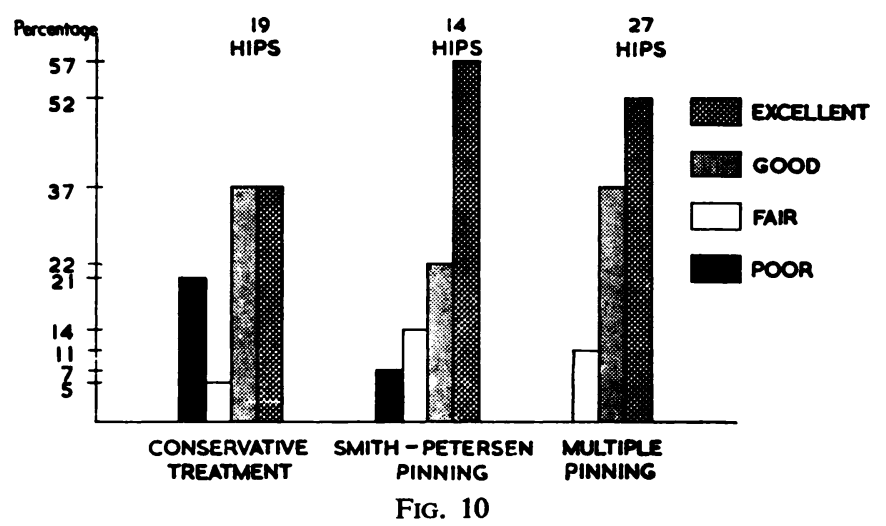

Results of conservative treatment, Smith-Petersen nailing and multiple pin fixation.

Forcible hammering under such circumstances may lead to further trauma and displacement of the epiphysis. Hall (1957) mentioned the large number of complications which result from the use of a Smith-Petersen nail. Wiberg (1959) has been more successful with the smaller Nyström nail but it too has its disadvantages. Newman (1956) reported the results in a series of cases in which multiple pins of the Austin Moore type were used. Multiple pins have also been employed at Exeter since 1950. A high proportion of successful results has been obtained (Table VII, Fig. 10). These pins can be inserted without much trauma, as little force is required to hammer them in and they will hold the epiphysis much in the same way as the crampons of a mountaineer's boots hold him on a slippery icy slope. Three or four are used and careful radiological technique is necessary to insert them. The relative ease with which a pin of small diameter can be inserted may be demonstrated by pushing it 
into a sorbo rubber ball. It will be found impossible to introduce a Smith-Petersen nail into the ball either by pressure or by hammering.

The pin needs a thread and nut at the end to prevent further penetration. It is, however, important that the thread is not continued far down the pin as this may make extraction difficult at a later date.

Internal fixation permits ambulation within four weeks of operation and weight bearing may be permitted at eight weeks. Fusion of the epiphysis has usually taken place within six to twelve months.

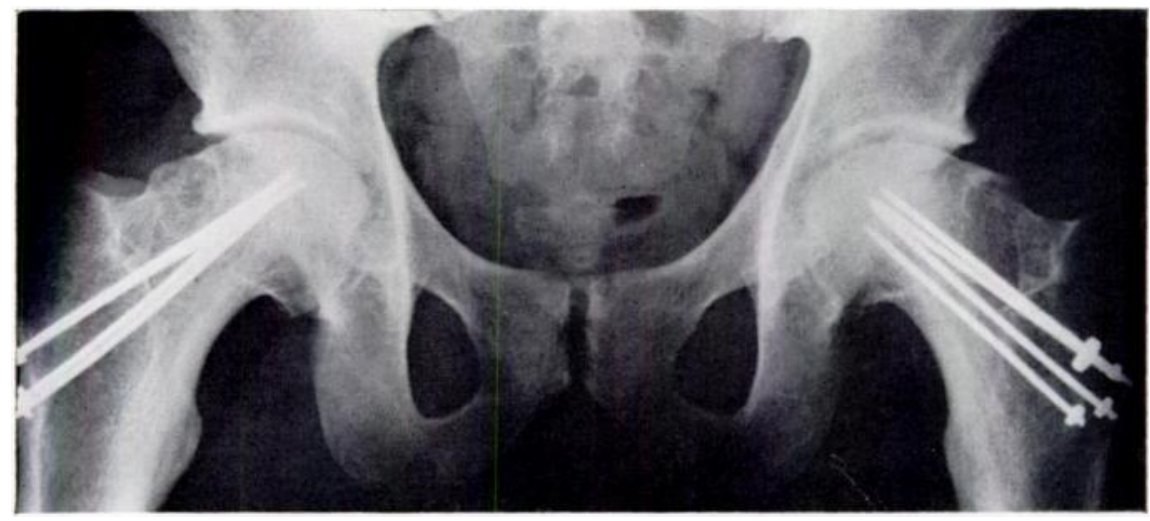

Fig. 11

Showing the anterior superior bony ridge in a pinning with more than 50 per cent displacement. Three years after pinning.

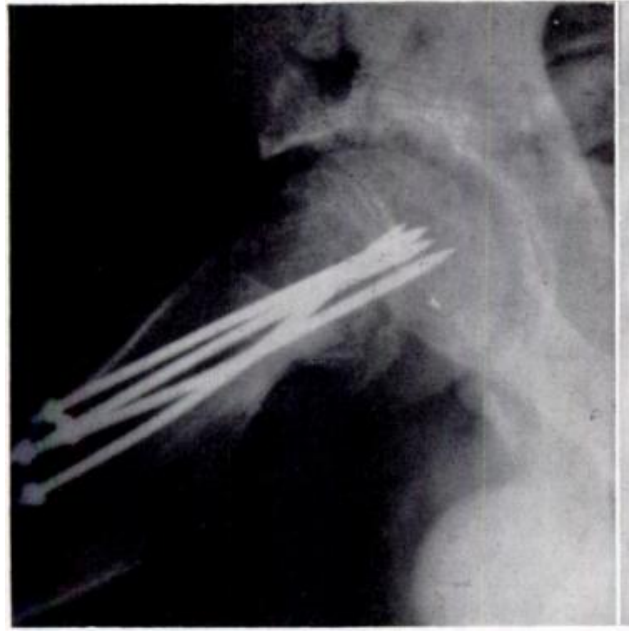

FiG. 12

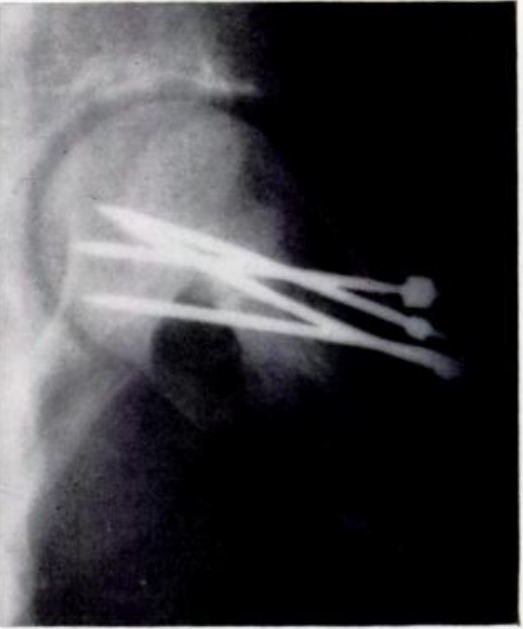

FiG. 13

Lateral views of the same hip joints as in Figure 11.

Treatment in patients with marked displacement-Pinning in the position of displacement should not be performed if the femoral head has slipped more than half its diameter because a bony ridge may develop at the antero-superior aspect of the neck which will limit abduction and medial rotation (Figs. 11 to 13), and lead to osteoarthritis later. Heyman, Herndon and Strong (1957) revived a conservative operation described by Elmslie (1913) to remove this bony prominence in the established case but the value of this procedure is doubtful because osteoarthritis may still occur in later years. 
When there is very marked displacement a gentle manipulative reduction should be attempted. If this is successful the epiphysis is fixed with three or four pins. If no alteration in position is possible it is best to perform an osteotomy in the trochanteric region, because it is unlikely that the epiphysis can be replaced by either more powerful manipulation or traction without endangering its blood supply and thus producing a poor result. The latter may already be inevitable because of interference with the blood supply caused by the original slip. It is not sufficiently well known that the epiphysis of the femoral head at this age is particularly susceptible to avascular necrosis, because of its precarious circulation, and that

TABLE VIII

RESULTS OF OSTEOTOMY

Hall's figures are in bold type

\begin{tabular}{|c|c|c|c|c|c|c|c|c|}
\hline & \multicolumn{2}{|c|}{ Excellent } & \multicolumn{2}{|c|}{ Good } & \multicolumn{2}{|c|}{ Fair } & \multicolumn{2}{|c|}{ Poor } \\
\hline & & & & Perce & tage & & & \\
\hline Cervical-9 hips & 11 & 23.7 & 22 & $35 \cdot 7$ & 11 & $4 \cdot 7$ & 56 & $35 \cdot 8$ \\
\hline Trochanteric -12 hips & 17 & $22 \cdot 2$ & 58 & $33 \cdot 3$ & 25 & $22 \cdot 2$ & 0 & $22 \cdot 2$ \\
\hline
\end{tabular}

this complication is common after fractures of the neck of the femur in children, even after fractures without displacement (Durbin 1959). Its frequency after an operation such as cervical osteotomy is therefore not surprising. Four out of nine of the hips in our series subjected to this operation developed avascular necrosis, and the procedure is therefore to be condemned.

The unacceptable immobile position or established coxa vara may cause disability with limitation of abduction and medial rotation of the hip. Any form of treatment is then a

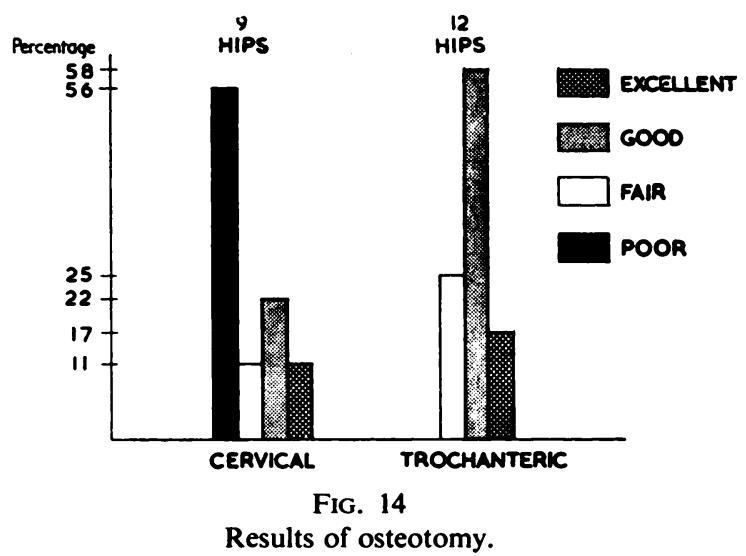

salvage procedure. The disability can be minimised by correcting the deformity of abduction and lateral rotation and restoring the arc of movement by wedge osteotomy in the trochanteric region. This procedure was revived by Perkins (1932). Intertrochanteric and subtrochanteric osteotomy appear to be equally successful, though in view of the displacement of the epiphysis the osteotomy should be low. After such corrective osteotomies remarkable remoulding occurs and some unpromising hips have gone on to present very successful results (Table VIII, Figs. 14 to 18$)$. 
Radiographs many years afterwards (in one case twenty-two years) reveal a hip with an excellent " joint space" and in this respect the results are similar to the effect of displacement osteotomy on certain osteoarthritic hips. After osteotomy the leg should be placed in about 45 degrees of abduction as this ensures that the new bone formed between the epiphysis and

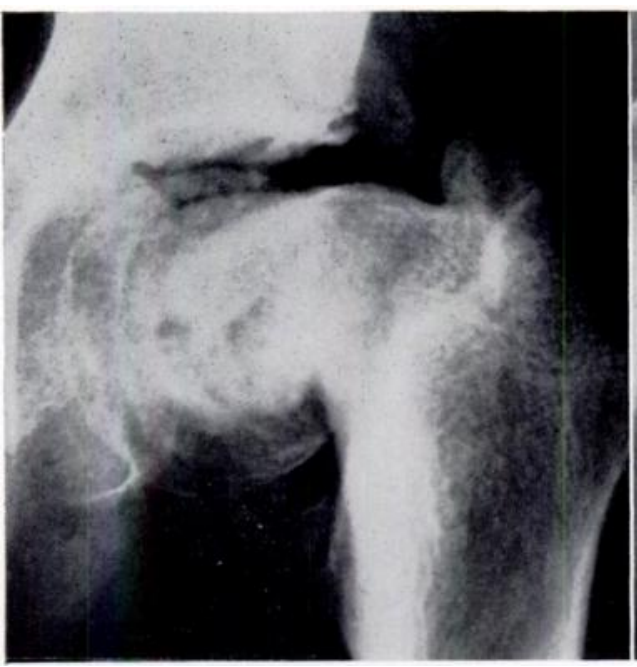

FIG. 15

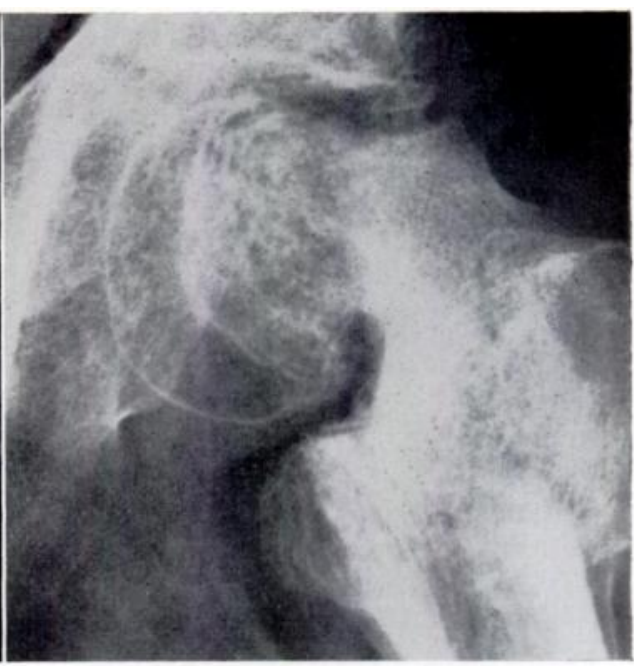

FIG. 16

Figure 15-A severe long-standing slip in a boy aged thirteen. Figure 16-Three months after trochanteric osteotomy and immobilisation in a plaster spica.

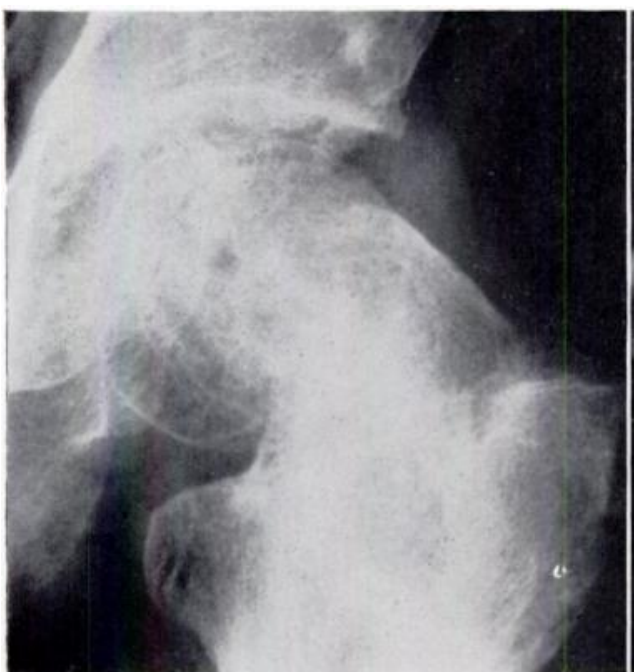

FiG. 17

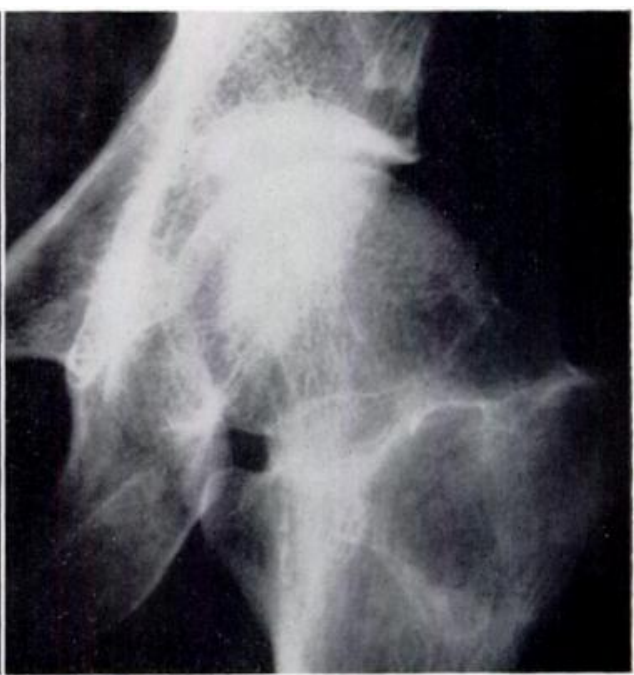

FIG. 18

Figure 17-Eight months after operation. There is remoulding of the neck of the femur. Figure 18 Fifteen years after operation there is normal movement in the hip joint. Furiher remoulding has occurred.

the neck of the femur will not be in contact with the acetabular rim when the leg is in the normal walking position after union of the osteotomy. Failure to do this may lead to the formation of a bony ridge resulting in restricted movement and the later development of osteoarthritic changes.

Avascular necrosis-Avascular necrosis occurs in two forms (Table IX)-massive necrosis of the epiphysis with preservation of a good joint space and acute necrosis of articular cartilage with diminution of the joint space (Waldenström 1930, Moore 1945, Jerre 1950, Lowe 1959). 


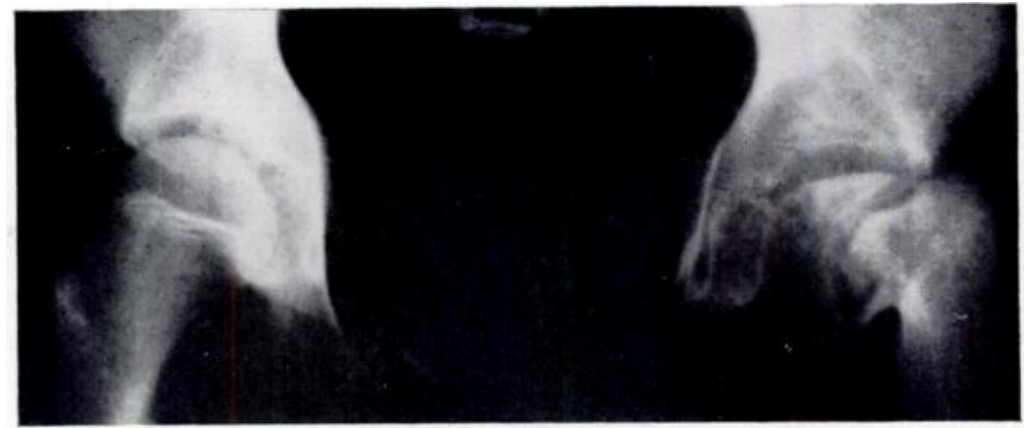

FIG. 19

A severe slip in a patient who had symptoms for three years. Skeletal traction was applied and subluxation of the hip resulted but the position of the epiphysis was unchanged. A subtrochanteric osteotomy was performed.

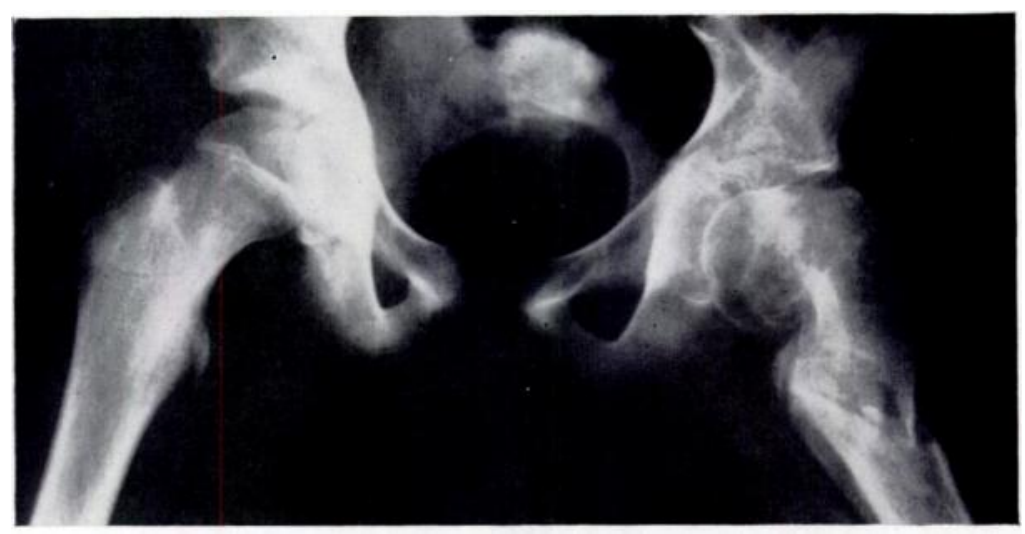

FIG. 20

Three months after subtrochanteric osteotomy, showing about 35 degrees of abduction at the site of osteotomy.

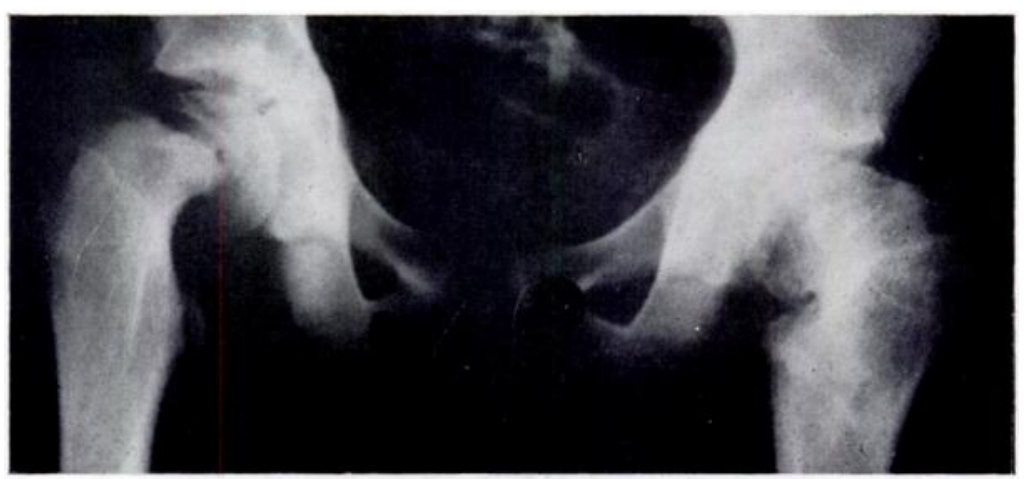

Fig. 21

Six months after the operation on the left hip there was sudden pain in the right hip and radiographs showed slipping of this epiphysis. The patient was walking without support at this time. 


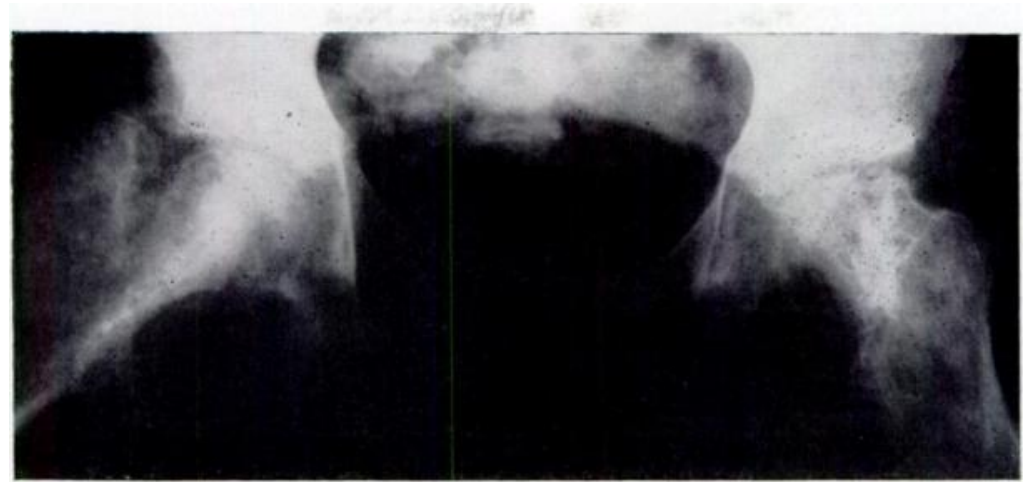

FiG. 22

Reduction of the displacement was achieved by manipulation, and plaster spica fixation for three months was employed.

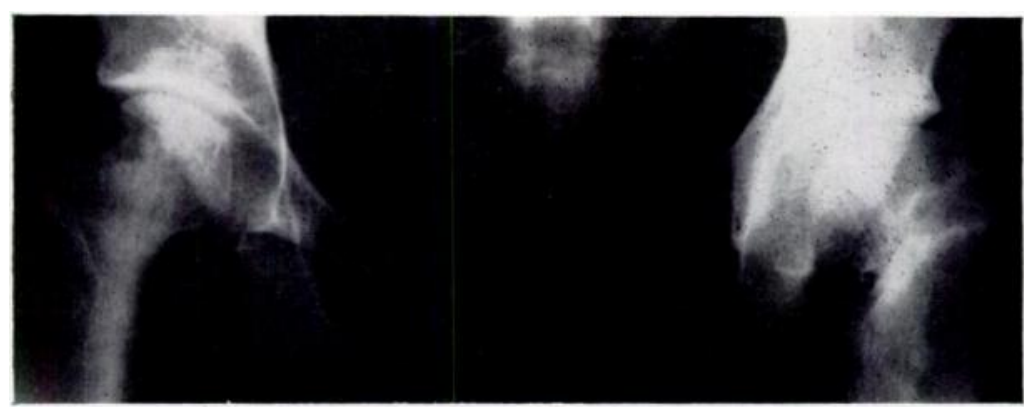

Fig. 23

Four years later. The left hip is excellent, but there are signs of deterioration in the right hip joint and cystic changes are present in the neck of the femur.

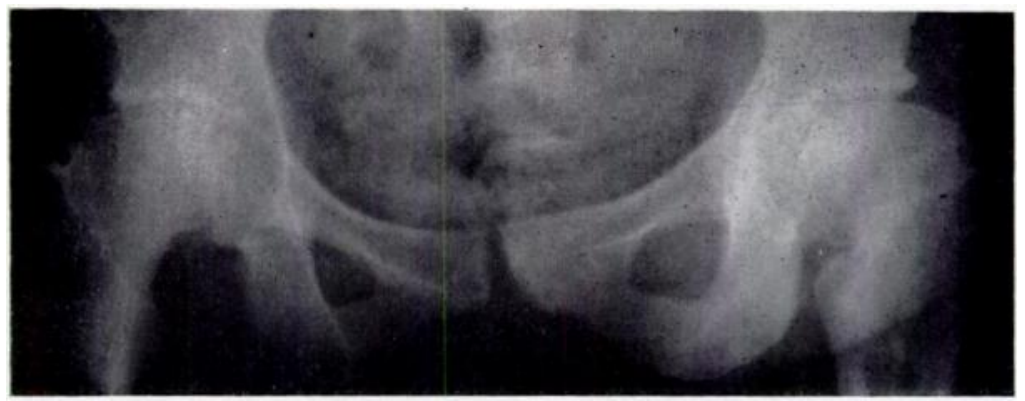

FiG. 24

Thirteen years after the onset of symptoms. The left hip joint is excellent but degenerative changes are present on the right side. 


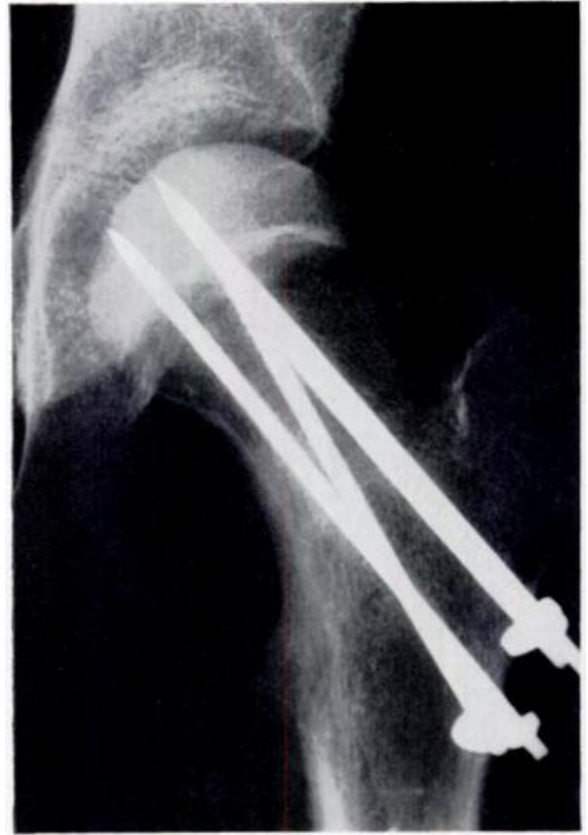

Fig. 25

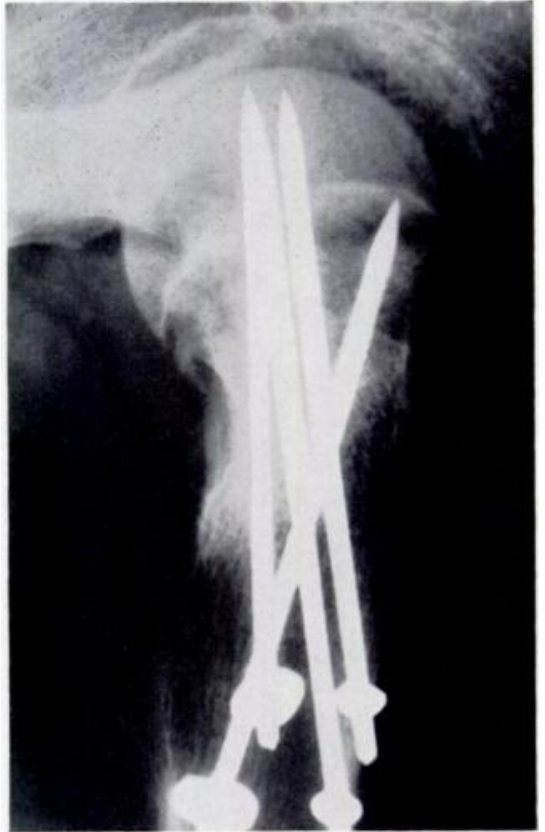

Fig. 26

Antero-posterior and lateral radiographs two months after reduction and multiple pinning; the epiphysis shows relative density suggestive of avascularity. A weight-relieving caliper was applied and worn for two years.

The first group has a better prognosis than the second, in which an ankylosed hip frequently results ( Table X, Figs. 19 to 24).

The two patients with avascular necrosis after insertion of multiple pins were provided with walking calipers which were worn for two years. Excellent revascularisation of the epiphysis took place in both (Figs. 25 to 28 ).

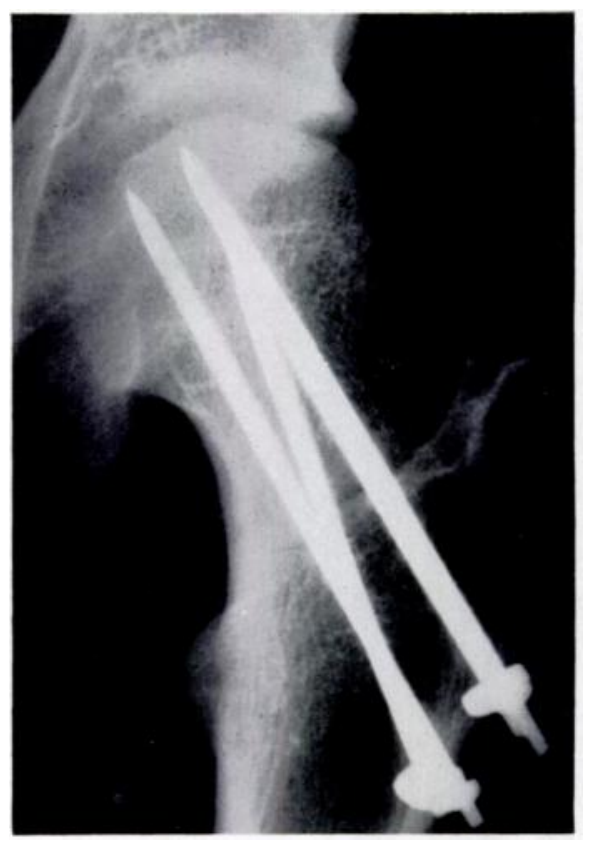

Fig. 27

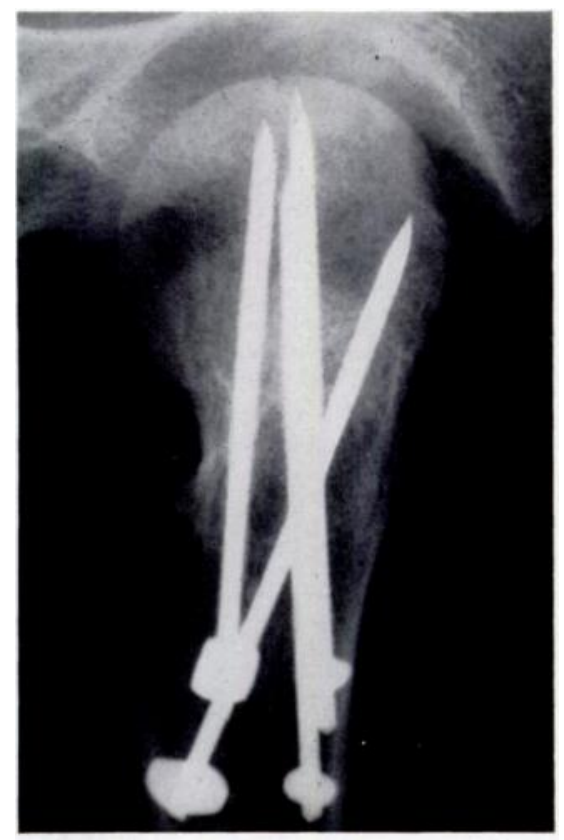

FIG. 28

Four years after pinning. Radiographs show an almost normal epiphysis. There is full range of joint movement. 
TABLE IX

TYPE OF NECROSIS

\begin{tabular}{|c|c|c|c|c|c|}
\hline Type of necrosis & $\begin{array}{c}\text { Cervical } \\
\text { osteotomy }\end{array}$ & $\begin{array}{c}\text { Manipulation } \\
\text { and } \\
\text { plaster }\end{array}$ & $\begin{array}{c}\text { Manipulation and } \\
\text { Smith-Petersen } \\
\text { nailing }\end{array}$ & $\begin{array}{c}\text { Manipulation } \\
\text { and } \\
\text { multiple pins }\end{array}$ & Result \\
\hline Necrosis of epiphysis & - & 1 & 1 & 2 & $\begin{array}{c}2 \text { good } \\
1 \text { fair } \\
1 \text { poor }\end{array}$ \\
\hline Necrosis of cartilage & 4 & 1 & 1 & - & $\begin{array}{l}1 \text { fair } \\
5 \text { poor }\end{array}$ \\
\hline
\end{tabular}

TABLE X

Results in Ten Hips with Avascular Necrosis

(12.3 per cent of series-compare Hall's 15.6 per cent)

\begin{tabular}{|c|c|c|c|c|c|c|}
\hline \multirow{2}{*}{\multicolumn{2}{|c|}{ Treatment }} & \multirow{2}{*}{$\begin{array}{c}\text { Number } \\
\text { of } \\
\text { hips }\end{array}$} & \multicolumn{3}{|c|}{ Results } & \multirow{2}{*}{ Remarks } \\
\hline & & & Good & Fair & Poor & \\
\hline Cervical osteotomy & . & 4 & & & 4 & All ankylosed \\
\hline Manipulation and plaster & . & 2 & & 1 & 1 & \\
\hline \multirow{2}{*}{\multicolumn{2}{|c|}{$\begin{array}{l}\text { Manipulation and Smith-Petersen nailing } \\
\text { Manipulation and multiple pinning }\end{array}$}} & 2 & & 1 & 1 & \multirow{3}{*}{$\begin{array}{l}\text { Subluxation nailing was caused in } \\
\text { one patient by skin traction without } \\
\text { medial rotation of the hip }\end{array}$} \\
\hline & & 2 & 2 & & & \\
\hline Total . & . & 10 & 2 & 2 & 6 & \\
\hline
\end{tabular}

\section{DISCUSSION}

It is possible to outline a scheme of treatment based upon the deductions drawn from this investigation. 1) Conservative treatment should be rejected because of its uncertain results. 2) When the condition is recognised at the stage of an acceptable amount of displacement the epiphysis is fixed with three or four pins. The patient rests in bed for four weeks after operation. Partial weight bearing is then allowed. Full weight bearing is permitted at the end of two months. 3) When recognition is delayed until the stage of an unacceptable amount of displacement (half diameter or more) the hip is gently manipulated under general anaesthesia. If reduction is achieved then three or four small pins are inserted. No weight bearing is allowed for two months. 4) When gentle manipulation fails to reduce such a displacement the deformity is corrected by trochanteric osteotomy. Intertrochanteric wedge osteotomy is easier to control than subtrochanteric. This operation restores the arc of movement and corrects the deformity of adduction and lateral rotation. If the slip is severe, wide abduction of about $\mathbf{4 5}$ degrees is required after osteotomy and it is an advantage if the limb is immobilised in plaster in flexion to bring the shaft of the femur into line with the posteriorly displaced epiphysis. A double spica is necessary for about three months.

\section{SUMMARY}

1. A series of eighty-one hips with slipped upper femoral epiphysis in sixty-three patients is reviewed.

2. The importance of early diagnosis is emphasised.

3. Conservative treatment is condemned.

4. In attempting reduction violent manipulation and strong traction must be avoided.

vol. 42 B, No. 2, MAY 1960 
5. In cases of slight displacement pinning in the position of displacement gives the best results.

6. Three or four small pins are recommended for fixation.

7. When the amount of slip is 50 per cent or more of the diameter of the head gentle manipulation should be tried and, if successful, followed by fixation with three or four pins.

8. The hip with an irreducible slip of 50 per cent or more should be treated by pertrochanteric or subtrochanteric osteotomy.

I wish to thank my colleagues at the Princess Elizabeth Orthopaedic Hospital, Exeter, for permission to include their cases, and Mr Leon Henry for three cases treated by intertrochanteric osteotomy. I am also much indebted to Mr James Piggot who assisted in the review of the patients.

\section{REFERENCES}

Bradford, E. H. (1892): Three Cases of the Separation of the Epiphysis at the Head of the Femur. Boston Medical and Surgical Journal, 126, 212.

Capener, N. (1956): In Modern Trends in Orthopaedics. (Second Series), p. 4. Edited by Sir Harry Platt. London: Butterworth \& Co. (Publishers) Ltd.

Durbin, F. C. (1959): Avascular Necrosis Complicating Undisplaced Fractures of the Neck of the Femur in Children. Journal of Bone and Joint Surgery, 41-B, 758.

Elmslie, R. C. (1913): Coxa Vara. Its Pathology and Treatment, p. 33. London: Henry Frowde Oxford University Press.

Ferguson, A. B., and Howorth, M. B. (1931): Slipping of the Upper Femoral Epiphysis. Journal of the American Medical Association, 97, 1,867.

HALL, J. E. (1957): The Results of Treatment of Slipped Femoral Epiphysis. Journal of Bone and Joint Surgery, 39-B, 659.

Heyman, C. H., Herndon, C. H., and Strong, J. M. (1957): Slipped Femoral Epiphysis with Severe Displacement. Journal of Bone and Joint Surgery, 39-A, 293.

HoworTH, M. B. (1957): Slipping of the Upper Femoral Epiphysis. In Clinical Orthopaedics, No. 10. Edited by A. F. De Palma. Philadelphia, London, Montreal: J. B. Lippincott Company.

Jerre, T. (1950): A Study in Slipped Upper Femoral Epiphysis. Acta Orthopaedica Scandinavica. Supplementum 6.

Keetley, C. B. (1888): A Case of Rachitis Adolescentium. Illustrated Medical News, $1,7$.

Klein, A., Joplin, R. J., and Reidy, J. A. (1948): The Treatment of Slipped Capital Femoral Epiphysis. Journal of the American Medical Association, 136, 445.

Lowe, H. G. (1959): Avascular Necrosis Complicating Slipped Upper Femoral Epiphysis. Journal of Bone and Joint Surgery, 41-B, 618.

Moore, R. D. (1945): Conservative Management of Adolescent Slipping of the Capital Femoral Epiphysis. Surgery, Gynecology and Obstetrics, 80, 324.

Newman, P. H. (1956): Surgical Treatment of Slipping of Upper Femoral Epiphysis. Journal of Bone and Joint Surgery, 38-B, 771.

PARÉ, A. (1572): De la fracture faite pres la jointure dudit os. In Oeuvres complètes (1840): Tome 2, Livre 13, Chapitre 21. Paris: J. B. Baillière.

Perkins, G. (1932): Treatment of Adolescent Coxa Vara. British Medical Journal, 1, 55.

SHEPHERD, M. M. (1954): Assessment of Function after Arthroplasty of the Hip. Journal of Bone and Joint Surgery, 36-B, 354.

StURrock, C. A. (1894): The After Results of Simple Separation of Epiphyses. Edinburgh Hospital Reports, 2 , 598.

Waldenström, H. (1930): On Necrosis of the Joint Cartilage by Epiphyseolysis Capitis Femoris. Acta Chirurgica Scandinavica, 67, 936.

Whitman, R. (1909): Further Observations on Injuries of the Neck of the Femur in Early Life. Medical Record, 75, 1.

Wiberg, G. (1959): Considerations on the Surgical Treatment of Slipped Epiphysis with Special Reference to Nail Fixation. Journal of Bone and Joint Surgery, 41-A, 253.

Wilson, P. D. (1938): The Treatment of Slipping of the Upper Femoral Epiphysis with Minimal Displacement. Journal of Bone and Joint Surgery, 20, 379. 